\title{
Progresión maligna de condilomas acuminados anogenitales asociados a Virus del Papiloma Humano de bajo riesgo en mujeres
}

\section{Malignant progression of anogenital condyloma acuminata associated with low-risk Human Papillomavirus in women}

\author{
Laura Daniela Sierra-Bossa* \\ Julián Ricardo Zapata-Rozo* \\ Diego Alejandro Rangel-Rivera**
}

*Estudiante de Medicina. Universidad Industrial de Santander. Seimed-UIS, Asociación de Sociedades Científicas de Estudiantes de Medicina de Colombia (ASCEMCOL). Bucaramanga, Colombia.

**Médico y cirujano. Residente de III año de Medicina Interna. Hospital Universitario de Santander. Profesor Cátedra. Universidad Industrial de Santander. Bucaramanga, Colombia.

Correspondencia: Sr. Julián Ricardo Zapata Rozo. Dirección: Cl 32 \#32-20, Barrio la Aurora, Bucaramanga, Colombia. Correo electrónico: jrzrozo@gmail. com

¿Cómo citar este artículo?: Sierra-Bossa LD, Zapata-Rozo JR, Rangel-Rivera DA. Progresión maligna de condilomas acuminados anogenitales asociados a Virus del Papiloma Humano de bajo riesgo en mujeres. MÉD.UIS.2020;33(1):9-11. doi: 10.18273/revmed.v33n1-2020001

El Virus del Papiloma Humano (VPH) es un agente infeccioso con tropismo por las células escamosas, transmitido por contacto (sexual o vertical) que tiene más de 100 serotipos distintos ${ }^{1}$. La Organización Panamericana de la Salud estima que el $90 \%$ de las personas serán infectadas a lo largo su vida²; por tanto, este virus constituye la infección viral de transmisión sexual más común y 40 de sus serotipos han sido relacionadas con lesiones anogenitales 3 . Sin embargo, la mayor parte de los contagios nunca presentan manifestaciones clínicas debido a que, usualmente, el sistema inmune es capaz de eliminar virus antes de que este pueda reservarse en el hospedero, deteniendo la infección desde el primer momento del contacto, por lo que la prevalencia de la infección es mucho menor². La prevalencia estimada de infección por VPH en los Estados Unidos y Europa corresponde al 9,6\% y 8,2\%, respectivamente. Se reporta también que la incidencia de condilomas es del 2 al $4 \%$ de la población con esta infección, con valores que han aumentado a lo largo del tiempo 3 .

Los serotipos de VPH se clasifican según su potencial oncogénico: las cepas 6 y 11, cuyo DNA viral no se integra al genoma de la célula infectada, son las principales causantes de verrugas genitales y se consideran de Bajo Riesgo (VPH-BR); en tanto que las cepas 16 y 18 , consideradas de Alto Riesgo (VPH$A R$ ), se asocian a lesiones displásicas y su potencial oncogénico se ha relacionado a la integración en el genoma de la célula del huésped ${ }^{4}$. Se ha descrito dentro de la patogenia, la inestabilidad genómica, inhibición de degradación de proteínas pro-apoptósicas y prolongación de efectos pro-mitóticos mediados por las proteínas E6 y E7 ${ }^{5,6}$. Dentro de las cepas de alto riesgo se incluyen también la 31, 33, 35, 39, 45, 51, $52,56,58$ y $59^{1}$.

Dentro de las lesiones como consecuencia de VPHBR predominan los condilomas acuminados; estos son crecimientos papilares patológicos que, en las mujeres, afectan principalmente el área de la vulva, vagina, cérvix, uretra, canal anal y piel perianal7. Su etiología es la infección por VPH, el 90\% por cepas 6 y 11 , por lo que no se consideran lesiones precancerosas y se presumen benignos. Su morfología puede ser sésil, pediculada o plana e histológicamente se describen como proliferaciones epiteliales ramificadas de epitelio escamoso estratificado y en la superficie epitelial "atipia coilocítica"4. 
Por otra parte, la patología maligna vulvar comprende lesiones neoplásicas con diferentes características desde el punto de vista clínico e histopatológico. Se incluye el Carcinoma Escamocelular (CEC) que puede ser VPH-dependiente, correspondiendo al 20$40 \%$ de los CECs de vulva, y se asocia principalmente con la cepa 16 y en menor frecuencia, 18 y 31. Esta variante también puede tener localización vaginal. El Carcinoma Condilomatoso (CCM) está asociado a VPH, usualmente cepa 16, sin embargo, se han descrito casos donde la cepa 6 es la única detectada7. En su fisiopatología se describe transferencia de $A D N$ viral, como E6 y E7, a la célula huésped y las proteínas producidas por estos genes inactivan genes supresores de tumores como $\mathrm{Rb}$ y $\mathrm{p} 53^{8}$. En condiciones normales, la proteína p16 fosforila la proteína $\mathrm{Rb}$, lo que inhibe la proliferación, además se ha descrito que, debido a la supresión de Rb por parte de E7 en la infección por VPH-16, la proteína p16 puede encontrarse elevada en lesiones altamente proliferativas y podría usarse como un indicador de alto potencial oncogénico ${ }^{9}$. En estos casos, usualmente hay infección con VPH sincrónica o metacrónica y lesiones asociadas a la misma. Por último, el Carcinoma Verrugoso (CVE) es una entidad muy poco frecuente que inicialmente fue asociada con VPH, sin embargo, esta asociación se encuentra en discusión actualmente debido a estudios más recientes en los cuales no se detectaron los ácidos nucleicos del virus ${ }^{4}$.

Masuda et al. en 2017 describieron el caso de una paciente de 43 años que estuvo en seguimiento de 3 años por un condiloma acuminado en cérvix, una biopsia evidenció engrosamiento epitelial con atipia, núcleos grandes y presencia de coilocitos $^{10}$. El espécimen de histerectomía permitió observar, además, invasión del estroma y metástasis a ganglios linfáticos pélvicos y paraaórticos y la inmunohistoquímica reveló inexpresión de p16. El diagnóstico final fue CCM y la tipificación del virus mostró infección por VPH-6 y negatividad para VPH-AR, incluyendo VPH-16. Hallazgos muy similares habían sido reportados previamente en un caso de carcinoma condilomatoso metastásico asociada a VPH-6 ${ }^{11}$. La no expresión de p16 en estos casos sugiere que estas lesiones surgieron a través de una vía diferente a la descrita con esta proteína y su inhibición por E7. Sin embargo, la calidad de la evidencia de estos hallazgos es muy baja y no hay reportes en la literatura de estudios que correlacionen condilomas acuminados con el riesgo de malignidad, ni tampoco un vínculo fisiopatológico claro entre el CCM y el VPH-6 o VPH-11. Se ha visto que, en la infección por VPH-BR, las uniones de E6 y E7 a p53 y Rb son débiles y la degradación de éstos últimos no ocurre ${ }^{8}$. Por tanto, la carcinogénesis de CCM sigue siendo desconocida.

Un estudio de 49 biopsias de lesiones neoplásicas vulvares intraepiteliales displásicas e invasivas, mostró que había una relación directamente proporcional entre el grado de displasia y la expresión de p16, de igual forma, las lesiones con mayor nivel de displasia tenían un mayor porcentaje de relación con infección por VPH-16. Sin embargo, algunas muestras de lesiones intraepiteliales con displasia grado 3 no tenían relación con VPH-16 y sí cepas de VPH-BR. Ninguna lesión vinculada a VPH-BR mostró inmunoreactividad para $\mathrm{p}^{16^{13}}$. En otro estudio de 60 biopsias de distintas lesiones asociadas a VPH, encontraron que las cepas de VPH-AR provocaron una fuerte respuesta a los biomarcadores p16, Ki67, importin- $\beta$, exportin5, Mcl1 y, en menor medida, PDL1, a diferencia de las muestras con VPH-BR que no presentaron esta sobreexpresión ${ }^{14}$. Lo anterior resalta la probable existencia de mecanismos - marcadores no descritos para las cepas de bajo riesgo en relación con su potencial carácter oncogénico. Adicionalmente, los hallazgos de inmunohistoquímica de estos estudios sugieren que las lesiones neoplásicas por VPH-AR suelen llevar una sobreexpresión de biomarcadores como el p16, cuya sobreexpresión puede ayudar a la diferenciación con lesiones de VPH-BR y sugerir la degradación de Rb, con un potencial proliferativo de mayor riesgo.

Por otra parte, se reportó un caso de coexistencia de condiloma acuminado con CEC y CVE en una paciente inmunocompetente que presentó infección por cepas de bajo y alto riesgo. La biopsia inicial no fue suficiente para confirmar malignidad, por lo que el diagnóstico de los carcinomas y su clasificación fue hecho posterior a una histerectomía, con estudios histopatológicos e inmunohistoquímicos ${ }^{15}$. Estos hallazgos concuerdan con otros estudios que señalan que, la infección por varias cepas puede producir condilomas acuminados que malignizan, o bien, una presentación sincrónica o anacrónica de diferentes neoplasias anogenitales asociadas a VPH, incluyendo las presentaciones malignas ${ }^{16}$.

Clásicamente, se ha considerado que en la infección por las cepas de $\mathrm{VPH}-6$ y $\mathrm{VPH}-11$ no hay riesgo de progresión oncogénica. Sin embargo, se han documentado algunos reportes de malignización con 
asociación de VPH-BR sin evidencia de VPH-AR. No hay claridad respecto de las condiciones que puedan actuar como factores predisponentes, pero algunos autores han asociado casos a inmunosupresiones congénitas y adquiridas ${ }^{17,18}$, transmisión vertical e infección por múltiples cepas ${ }^{17,19}$. La morfología atípica de las lesiones verrugosas anogenitales no ha sido vinculada a atipicidad histológica o riesgo de progresión maligna ${ }^{20}$.

En conclusión, las cepas de VPH-BR suelen causar lesiones benignas. Sin embargo, hay casos descritos de malignización y de coexistencia con lesiones epiteliales de alto grado, CEC, CVE y, especialmente, CCM, sin que haya infección por VPH-AR. Es posible que exista un subtipo CCM agresivo que, bajo condiciones clínicas particulares pueda surgir de una cepa de VPH-BR. Sin embargo, esta hipótesis necesita más estudios con mayor número de pacientes. Los mecanismos oncogénicos del VPH$\mathrm{BR}$ son inciertos y podrían relacionarse a factores idiosincráticos, genéticos, de exposición ambiental y de mecanismos de inflamación crónica ${ }^{12}$, difiriendo de la vía de inhibición de supresores de tumor por las proteínas E6 y E7. Se requieren estudios que permitan poner a prueba estas hipótesis y conocer más de la fisiopatología de las neoplasias asociadas a VPH-BR, así como estudios de caracterización clínico-patológica que permitan identificar variables asociadas a la progresión de malignidad.

\section{Referencias bibliográficas}

1. Jameson J. Harrison, principios de medicina interna, 20e. 20th ed. Ciudad de México: M\&N Medical Solutrad, S.A \& McGrawHill Education; 2019.

2. Revilla, F. (2020). OPS/OMS / Acerca del VPH. Pan American Health Organization / World Health Organization. Retrieved 26 March 2020, from https://www.paho.org/hq/index.php?option=com_content\&vie $\mathrm{w}=$ article\&id=14718:about-hpv-vaccine\&Itemid =72405\&lang=es.

3. NELSON E, BOGLIATTO F, STOCKDALE C. Vulvar Intraepithelial Neoplasia (VIN) and Condylomata. Clinical Obstetrics and Gynecology. 2015;58(3):512-525.

4. Kumar, V. ROBBINS \& COTRAN Structural and Functional. 9th ed. ELSEVIER - HEALTH SCIENCE. 2015;991.

5. Valencia Mayoral P, Ancer Rodríguez J. Patología. 1st ed. México [etc.]: McGrawHillEducation; 2014.

6. Arenas Guzmán R. Dermatología. 7th ed. Ciudad de México: McGRAW-HILL INTERAMERICANA EDITORES,S.A.

7. Strickland, S. (2020). Condyloma. Pathologyoutlines.com. Retrieved 26 March 2020, from https:/www.pathologyoutlines. com/topic/vulvacondyloma.html.

8. Doorbar J, Quint W, Banks L, Bravo I, Stoler M, Broker T et al. The Biology and Life-Cycle of Human Papillomaviruses. Vaccine. 2012;30:F55-F70.

9. Klaes R, Friedrich T, Spitkovsky D, Ridder R, Rudy W, Petry $\mathrm{U}$ et al. Overexpression of p16INK4A as a specific marker for dysplastic and neoplastic epithelial cells of the cervix uteri. International Journal of Cancer. 2001;92(2):276-84.

10. Masuda M, Abiko K, Minamiguchi S, Murakami R, Baba T, Konishi I. Case of rapidly progressing condylomatous squamous cell carcinoma of the uterine cervix associated with lowrisk human papillomavirus type 6. Journal of Obstetrics and Gynaecology Research. 2017;44(3):583-7.

11. Padberg B, Bode B, Zimmermann D. Metastatic warty (condylomatous) carcinoma of the uterine cervix associated with low-risk HPV type 6. Acta Cytologica 2006;50(2):235-8. PMDI: 16610699

12. del Pino M, Rodriguez-Carunchio L, Ordi J. Pathways of vulvar intraepithelial neoplasia and squamous cell carcinoma. Histopathology. 2012;62(1):161-175.

13. Rufforny I, Wilkinson E, Liu C, Zhu H, Buteral M, Massoll N. Human Papillomavirus Infection and p16INK4a Protein Expression in Vulvar Intraepithelial Neoplasia and Invasive Squamous Cell Carcinoma. Journal of Lower Genital Tract Disease. 2005;9(2):108-113.

14. Nuovo, G., Schwartz, Z., \& Magro, C. (2019). A comparison of the detection of biomarkers in infections due to low risk versus high-risk human papillomavirus types. Annals Of Diagnostic Pathology, 41, 57-61. https://doi.org/10.1016/j. anndiagpath.2019.05.010

15. ErmanVlahovic M, Vlahovic J, Mrcela M, Hrgovic Z. Coexistence of Condylomata Acuminata with Warty Squamous Cell Carcinoma and Squamous Cell Carcinoma. Medical Archives. 2017;71(1):72.

16. Srodon M, Stoler M, Baber G, Kurman R. The Distribution of Low and High-risk HPV Types in Vulvar and Vaginal Intraepithelial Neoplasia (VIN and VaIN). The American Journal of Surgical Pathology. 2006;30(12):1513-8.

17. Léonard B, Kridelka F, Delbecque K, Goffin F, Demoulin S, Doyen J et al. A Clinical and Pathological Overview of Vulvar Condyloma Acuminatum, Intraepithelial Neoplasia, and Squamous Cell Carcinoma. BioMed Research International. 2014;2014:1-11.

18. Toboni M, Bevis K. Vulvar Cancer as a Result of GATA2 Deficiency, a Rare Genetic Immunodeficiency Syndrome. Obstetrics \& Gynecology. 2018;132(5):1112-5.

19. Gross G. Genitoanal Human Papillomavirus Infection and Associated Neoplasias. Human Papillomavirus. 2014;45:98-122.

20. Kumar P, Bhari N, Gupta V, Ramachandran V, Arava S, Dar L et al. Atypical morphology of anogenital warts is not a marker of atypical histology or of infection to the high-risk human papillomavirus genotypes. International Journal of Dermatology. 2017;56(10):1017-1021. 